\title{
A concise model for evaluating water electrolysis
}

\author{
Muzhong Shen ${ }^{a, *}$, Nick Bennett ${ }^{a}$, Yulong Ding ${ }^{b}$, Keith Scott ${ }^{c}$ \\ ${ }^{a}$ Department of Mechanical \& Design Engineering, University of Portsmouth, Portsmouth PO1 3DJ, UK \\ ${ }^{\mathrm{b}}$ School of Process, Environmental and Materials Engineering, University of Leeds, Leeds LS2 9JT, UK \\ ${ }^{\mathrm{C}}$ School of Chemical Engineering and Advanced Materials, University of Newcastle upon Tyne, Newcastle upon Tyne NE1 7RU, UK
}

\section{A R T I C L E I N F O}

Article history:

Received 30 July 2010

Received in revised form

2 December 2010

Accepted 7 December 2010

Available online 15 September 2011

Keywords:

Water electrolysis

Hydrogen production

Electrochemical kinetics

Concise model

Butler-Volmer equation

\begin{abstract}
A B S T R A C T
To evaluate water electrolysis in hydrogen production, a concise model was developed to analyze the current-voltage characteristics of an electrolytic cell. This model describes the water electrolysis capability by means of incorporating thermodynamic, kinetic and electrical resistance effects. These three effects are quantitatively expressed with three main parameters; the thermodynamic parameter which is the water dissociation potential; the kinetic parameter which reflects the overall electrochemical kinetic effect of both electrodes in the electrolytic cell, and the ohmic parameter which reflects the total resistance of the electrolytic cell. Using the model, different electrolytic cells with various operating conditions can be conveniently compared with each other. The modeling results are found to agree well with experimental data and previous published work.

Copyright @ 2010, Hydrogen Energy Publications, LLC. Published by Elsevier Ltd. All rights
\end{abstract}

reserved.

\section{Introduction}

Hydrogen is a clean fuel for fuel cell applications. Combined with solar cell systems or wind power systems, hydrogen produced with water electrolysis will play an important role as an energy carrier for sustainable development in future [1]. For reducing operating costs and increasing energy efficiency, there are many techniques and research works [2-9] concerning the water electrolysis process. Compared with traditional alkaline electrolysis [4], in which corrosive potassium hydroxide $(\mathrm{KOH})$ solution is used as the electrolyte, proton exchange membrane (PEM) electrolysis has acquired a lot of attention for its advantages of ecological cleanliness, high degree of hydrogen purity, and easy maintenance [10]. In general, all these research works try to improve the electrolysis performance from two aspects; to increase electrochemical activity of electrodes and to reduce the total resistance of the electrolytic cell.
The water electrolysis performance is normally evaluated with the current-voltage characteristics of an electrolytic cell as shown in Fig. 1. Several models [11-13] have been developed to try to simply and effectively simulate the current-voltage characteristics of PEM electrolysis for hydrogen production. With present models, the cell voltage is basically described as the sum of Nernst voltage, resistive voltage drop, and anode and cathode overpotentials [14]. The anode and cathode overpotentials are usually obtained via the Butler-Volmer kinetic equation. To solve the Butler-Volmer equation, two parameters of exchange current density for the anode and the cathode are required to describe the electrode activities. Additionally, the symmetrical factors of the equation also need to be assumed as a specific number [15]. The exchange current density depends on the temperature and the roughness of the electrode surface [13]. In most case, the values of exchange current density for anode and cathode are

\footnotetext{
* Corresponding author.

E-mail address: muzhong.shen@port.ac.uk (M. Shen).
}

0360-3199/\$ - see front matter Copyright @ 2010, Hydrogen Energy Publications, LLC. Published by Elsevier Ltd. All rights reserved. doi:10.1016/j.ijhydene.2010.12.029 


\begin{tabular}{|c|c|c|c|}
\hline \multicolumn{2}{|c|}{ Nomenclature } & & the pre-exponential factor \\
\hline PEM & proton exchange membrane & $E_{\text {act, }, \mathrm{i}}$ & the activation energy \\
\hline $\mathrm{KOH}$ & potassium hydroxide & $\mathrm{a}, \mathrm{c}$ & anode, cathode \\
\hline & reversible anode potential & A & surface area, $\mathrm{cm}^{2}$ \\
\hline$E_{\text {anode }}^{0}$ & reversible cathode potential & $\dot{\mathrm{N}}_{\mathrm{H}_{2}}$ & hydrogen producing rate, $\mathrm{mol} \mathrm{s}^{-1}$ \\
\hline$E_{\text {cell }}^{0}$ & reversible cell potential & $\dot{\mathrm{N}}_{\mathrm{O}_{2}}$ & oxygen producing rates, $\mathrm{mol} \mathrm{s}^{-1}$ \\
\hline$R^{c e n}$ & gas constant, $8.3145 \mathrm{~J} \mathrm{~mol}^{-1} \mathrm{~K}^{-1}$ & I & cell current, A \\
\hline F & Faraday constant, $96,485 \mathrm{C} \mathrm{mol}^{-1}$ & $r$ & cell resistance, $\Omega$ \\
\hline $\mathrm{T}$ & the absolute temperature, $\mathrm{K}$ & V & cell potential, $V$ \\
\hline$p$ & pressure, $\mathrm{Pa}$ & $P$ & process, W \\
\hline$J$ & the current density, $\mathrm{A} \mathrm{cm}^{-2}$ & $E_{0}$ & water dissociation potential, $\mathrm{V}$ \\
\hline $\begin{array}{l}\eta_{\text {act }, i} \\
J_{0, i}\end{array}$ & $\begin{array}{l}\text { the activation overpotential } \\
\text { exchange current density }\end{array}$ & $\mathrm{K}$ & power conversion coefficient, $\Omega^{-1}$ \\
\hline
\end{tabular}

different to each other [11,12]. All these make it difficult to predict the water electrolysis performance directly.

In this paper, a new model is proposed to simulate the current-voltage characteristics of water electrolysis. The water electrolysis capability of an electrolytic cell was expressed through three main parameters which reflect the thermodynamic effect, the overall electrochemical kinetic effect and the total resistance of the electrolytic cell. With these parameters, different electrolytic cells in various operating conditions can be conveniently compared with each other. An experiment was designed to investigate the water electrolysis process with different electrode materials and cell resistances. The modeling results are compared and validated with the experimental data and with previously published work.

\section{Model description}

\subsection{The fundamentals of water electrolysis}

Water electrolysis is the process of dissociating water molecules into hydrogen and oxygen gas using electrical power. The electrochemical reaction happens on both anode and cathode.

At the anode:

$\mathrm{H}_{2} \mathrm{O}(\mathrm{l}) \Leftrightarrow 2 \mathrm{H}^{+}+\frac{1}{2} \mathrm{O}_{2}+2 \mathrm{e} \quad E_{\text {anode }}^{0}\left(25^{\circ} \mathrm{C}\right)=1.23 \mathrm{~V}$

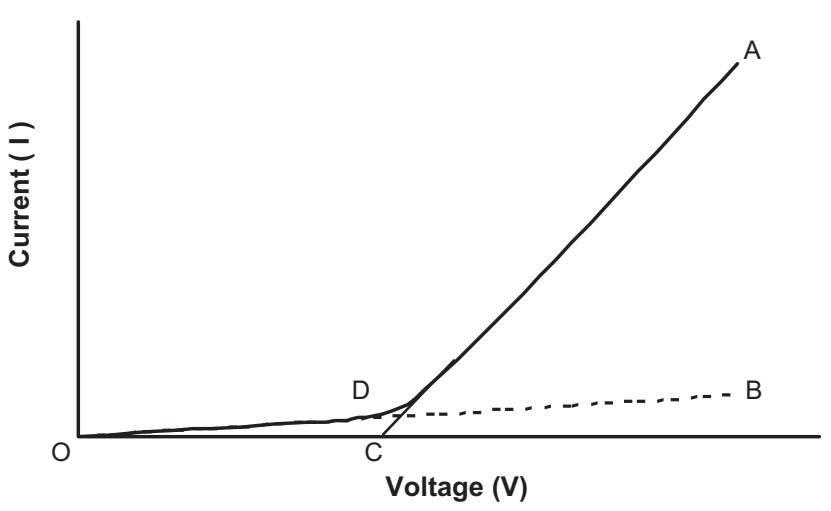

Fig. 1 - The relationship between the current versus potential of water electrolysis.
At cathode:

$2 \mathrm{H}^{+}+2 \mathrm{e} \Leftrightarrow \mathrm{H}_{2} \quad \mathrm{E}_{\text {cathode }}^{0}\left(25^{\circ} \mathrm{C}\right)=0 \mathrm{~V}$

The net reaction in the electrolytic cell is:

$\mathrm{H}_{2} \mathrm{O}(\mathrm{l}) \Leftrightarrow \mathrm{H}_{2}+\frac{1}{2} \mathrm{O}_{2} \quad E_{\text {cell }}^{0}\left(25^{\circ} \mathrm{C}\right)=1.23 \mathrm{~V}$

The reversible potential reflects the thermodynamic effect of electrochemical reaction. The Nernst equation of water electrolysis is shown as equation (4) [16].

$E_{\text {cell }}^{0}=1.23-0.9 \times 10^{-3}(\mathrm{~T}-298)+\frac{R T}{4 \mathrm{~F}} \ln \left(\frac{p_{\mathrm{H}_{2}}^{2} \cdot p_{\mathrm{O}_{2}}}{p_{\mathrm{H}_{2} \mathrm{O}}}\right)$

where $p_{\mathrm{H}_{2}}, p_{\mathrm{O}_{2}}$ and $p_{\mathrm{H}_{2} \mathrm{O}}$ are the partial pressures of hydrogen, oxygen and water vapor respectively. Although the reversible potential of water electrolysis at $25{ }^{\circ} \mathrm{C}$ is $1.23 \mathrm{~V}$, the water dissociation potential is influenced by the catalyst activity of electrodes. When platinum is used as the anode and cathode, the dissociation potential is $1.68 \mathrm{~V}$ [9]. The dissociation potential can be reduced to $1.4 \mathrm{~V}$ when platinum and iridium are used as electrocatalysts $[2,6,9,17]$. The electrochemical properties of electrodes not only influence the kinetic effects of water electrolysis, but also influence the mechanism of electrochemical reaction which decides the value of water dissociation potential.

The kinetic effect of water electrolysis is conventionally expressed with the Butler-Volmer equation via the activation overpotential of both electrodes which can be expressed as equation (5) [12].

$\eta_{\mathrm{act}, \mathrm{i}}=\frac{R T}{F} \sinh ^{-1}\left(\frac{J}{2 J_{0, \mathrm{i}}}\right)=\frac{R T}{F} \ln \left[\frac{J}{2 J_{0, \mathrm{i}}}+\sqrt{\left(\frac{J}{2 J_{0, \mathrm{i}}}\right)^{2}+1}\right], \mathrm{i}=\mathrm{a}, \mathrm{c}$

where $\eta_{\text {act,i }}$ is the activation overpotential and subscripts a and $c$ represent anode and cathode respectively; $J$ is the operating current density; $J_{0, i}$ is the exchange current density. The exchange current density can be expressed as equation (6).

$J_{0, i}=J_{i}^{r e f} \exp \left(\frac{E_{a c t, i}}{R T}\right), i=a, c$ 
In the water electrolysis process, the activation overpotentials of anode and cathode are normally different to each other [12] which reflect their different catalytic activities. However the ratio of electrochemical reaction rate on cathode to anode is not decided by their catalytic activities, but only by the stoichometric ratio, because the electric current passing through the cathode always equals the current pass through the anode in electrolysis process. The hydrogen and oxygen producing rates are expressed with eqs. (7) and (8) respectively [13].

$\dot{\mathrm{N}}_{\mathrm{H}_{2}}=\frac{\mathrm{JA}}{2 \mathrm{~F}}$

$\dot{\mathrm{N}}_{\mathrm{O}_{2}}=\frac{J \mathrm{~A}}{4 \mathrm{~F}}$

\subsection{An assumption and model expression}

The water electrolysis process and the fuel cell process are similar, but working in the opposite direction [18]. Our previous work [19] has investigated the fuel cell performance from the viewpoint of power conservation. Same as the fuel cell performance, we assume the power consumed in the water electrolysis process is proportional to the square of the potential difference between the cell and the water dissociation potentials. This assumption can be expressed as equation (9).

$P \propto\left(V-E_{0}\right)^{2}$

where $P$ is the power consumed in the water electrolysis process; $V$ is cell potential and $E_{0}$ is the water dissociation potential. In water electrolysis, cell resistance influences the cell performance by reducing the efficiency and consuming energy. The cell resistance includes electrode resistance, electrolyte resistance and the interfacial resistance. If the sum of these resistances of an electrolytic cell is $r$, the ohmic voltage drop or potential drop over the total resistance is Ir when current I pass through the electrolytic cell. In this case, the practical potential over the electrodes equals the cell potential reduced by the voltage drop over the cell resistance. Hence, equation (9) is modified with equation (10) and expressed as equation (11).

$\mathrm{P} \propto\left(\mathrm{V}-\mathrm{Ir}-\mathrm{E}_{0}\right)^{2}$

$P=K\left(V-I r-E_{0}\right)^{2}$

According to equation (11), $\mathrm{K}$ is proportional coefficient of power conversion which reflects the capability of an electrolytic cell to convert electrical energy to chemical energy. Different electrolytic cells with various operating conditions, such as pressure/temperature/catalyst loading etc., have different values of $\mathrm{K}$. From dimensional analysis, the unit of power conversion coefficient is $\mathrm{Ohm}^{-1}\left(\Omega^{-1}\right)$. However, this is not relevant to the concept of conductivity or resistance. Considering the power consumed by the cell resistance, the power applied in the electrolytic cell follows equation (12):

$\mathrm{I} \times \mathrm{V}-\mathrm{I}^{2} r=\mathrm{K}\left(\mathrm{V}-\mathrm{Ir}-\mathrm{E}_{0}\right)^{2}$

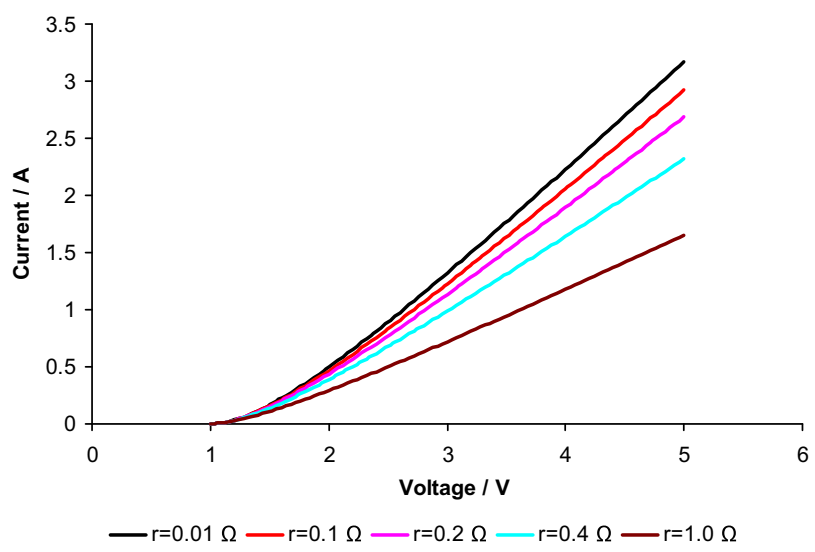

Fig. 2 - The electrolysis curve of equation (13) with different resistances.

From equation (12), the relationship between the potential versus current can be expressed with equation (13).

$I=\frac{V+2 K r\left(V-E_{0}\right)-\sqrt{V^{2}+4 K r E_{0}\left(V-E_{0}\right)}}{2 r(1+K r)}$

\subsection{Characteristics of the mathematical model}

Equation (13) expresses the performance of an electrolytic cell. The three parameters, $E_{0}, r$ and $K$, influence the performance of an electrolytic cell respectively. When $E_{0}$ equals $1.0 \mathrm{~V}$, Fig. 2 shows the relationship between current versus potential of equation (13) with different resistances if the power conversion coefficient $K$ is $1.0 \Omega^{-1}$. Fig. 3 shows the relationship between current versus potential of equation (13) with different power conversion coefficients if the resistance $r$ is $0.1 \Omega$.

Figs. 2 and 3 show the fundamental characteristics of the mathematical function of equation (13) with parameters of $E_{0}$, $r$, and $K$. The value of $E_{0}$ decides the start point of the electrolysis curve which represents water dissociation potential. The value of resistance $r$ is relevant to the slope of electrolysis curve. The value of kinetic parameter $\mathrm{K}$ influences both the slope and the curve shape of electrolysis curve, $0 \leq \mathrm{K}<\infty$. Considering the extreme condition, when the value of $\mathrm{K}=0$, equation (13) will change to $I=0$, which means the cell current

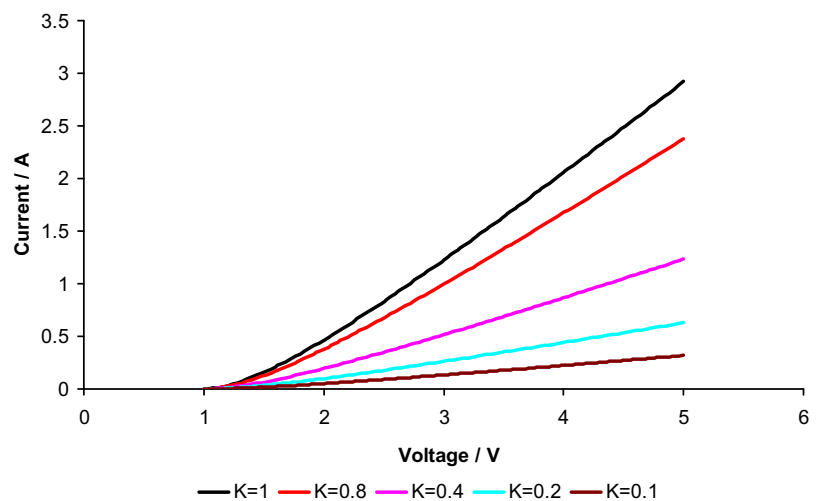

Fig. 3 - Electrolysis curve of equation (13) with different power conversion coefficient. 
cannot pass through the electrochemical cell and an electrochemical reaction will not happen if the electrodes have no kinetic activities. When the value of $K \rightarrow \infty$, the equation (13) tends to equation (14) as below:

$I=\left(V-E_{0}\right) / r$

The mathematical function of equation (14) represents a line which passes through the point $\left(E_{0}, 0\right)$ with a slope of $1 / r$, which means the performance of an electrochemical cell will act like a pure resistance if the overall kinetic activity of electrodes tends to infinity.

\section{Experimental procedure}

To validate the assumption and the model, experiments were designed to investigate the water electrolysis process with different electrode materials and cell resistances. The experiments were made using two cells interconnected with a tube of adjustable length filled with liquid electrolyte. $1 \mathrm{M}$ sulfuric acid (supplied by Aldrich) was used as the electrolyte solution. The electrodes were made of bright platinum mesh, size $50 \times 50 \mathrm{~mm}$ (supplied by Goodfellow). A graphite electrode, size $70 \times 7 \times 2 \mathrm{~mm}$, was used as the cathode in the experiment for comparison. The volume of each electrolytic cell was $250 \mathrm{ml}$. A tube with inner diameter of $7.5 \mathrm{~mm}$ was used to connect both electrolytic cells. The length of the tube $L$ was adjusted to $70 \mathrm{~mm}$ and $130 \mathrm{~mm}$ to obtain different electrolytic cell resistances. The electric current and potential were measured with a multimeter, mode IDM 97 (supplied by ISOTech), and the power source with mode PL330-32V-3A (supplied by Thurlby-Thandar).

\section{Results and discussion}

Fig. 1 shows a typical water electrolysis curve. The cell current increases with cell potential following the curve ODA in Fig. 1. In the curve segment $\mathrm{OD}$, the current increases very slowly with the cell potential. In this stage the electrolysis is not in process. When the cell potential increases above the potential of point $D$, the current increases substantially, not following the curve OB but diverting to curve DA. The electrochemical reaction is started at point $D$. The potential value of point $D$ is defined as the water dissociation potential $E_{0}$ in this paper. The cell current at point $\mathrm{D}$ is defined as the background current which is used to modify the practical simulation. In theory, when cell potential $\mathrm{V}<E_{0}$, the cell current is zero. The start current of model calculation in Figs. 2 and 3 is zero. However in practical situation, a small current always existed in electrolytic cell when operating voltage is smaller than its dissociation potential. The background current is around $0.5 \mathrm{~mA}$ in our experiments.

\subsection{Simulation of water electrolysis with different resistance}

Fig. 4 shows the experimental and modeling results of the current-potential relationship of water electrolysis with two

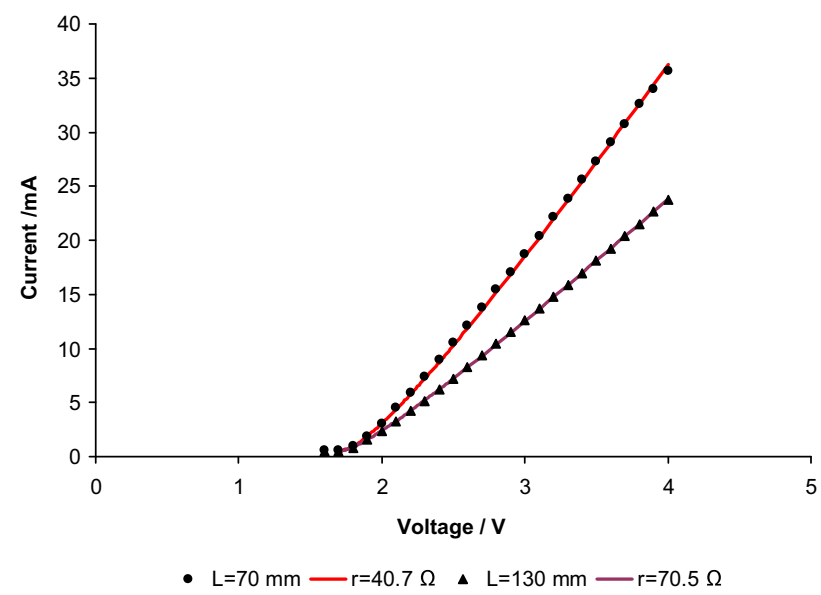

Fig. 4 - Experiment data of water electrolysis with different resistance and their modeling results with equation (13).

different resistances. When the tube length $\mathrm{L}$ was $70 \mathrm{~mm}$, water electrolysis started at potential of $1.70 \mathrm{~V}$ with background current of $0.59 \mathrm{~mA}$. The value of water dissociation potential $E_{0}$ was $1.70 \mathrm{~V}$. From experimental voltage and current data, and using the method of nonlinear least square regression, the power conversion coefficient and the value of cell resistance are obtained as $K=0.127 \Omega^{-1}, r=40.7 \Omega$. The nonlinear least square regression problem was solved by the Gauss-Newton method implemented in MATLAB. Substituting the water electrolysis parameters of $E_{0}=1.70 \mathrm{~V}$, $K=0.127 \Omega^{-1}$ and $r=40.7 \Omega$ into equation (13), the current-potential relationship can be expressed as equation (15).

$I=\frac{V+10.34(V-1.7)-\sqrt{V^{2}+35.15(V-1.7)}}{502.15}$

Considering the background current of $0.59 \mathrm{~mA}$, the electrolysis equation is expressed by equation (16) with the unit of current in $\mathrm{mA}$. The simulation results using equation (16) are shown as " $r=40.7 \Omega$ ", and the experiment data are shown as "L $=70 \mathrm{~mm}$ " in Fig. 4.

$I=0.59+\frac{V+10.34(V-1.7)-\sqrt{V^{2}+35.15(V-1.7)}}{502.15} \times 1000$

With the same electrodes and operating condition, when the cell tube length $\mathrm{L}$ extended to $130 \mathrm{~mm}$, the experiment shows that water electrolysis started at potential $1.70 \mathrm{~V}$ with background current of $0.5 \mathrm{~mA}$. The water electrolysis parameters are obtained from the experimental data with: $E_{0}=1.7 \mathrm{~V}$, $K=0.127 \Omega^{-1}$ and $r=70.5 \Omega$. The modeling equation can, therefore, be achieved by applying the water electrolysis parameters in equation (13). In Fig. 4, the simulation results are shown as " $r=70.5 \Omega$ ", and the experiment data are shown as " $\mathrm{L}=130 \mathrm{~mm}$ ".

Comparing the experimental data and modeling results with different cell resistances, the cell resistance $(r)$ changes from $40.7 \Omega$ to $70.5 \Omega$, an increase of $29.8 \Omega$. If the conductivity of $1 \mathrm{M}$ sulfuric acid is $440 \mathrm{mS} \mathrm{cm}^{-1}[20,21]$, the resistance of the extension part of the sulfuric acid in the tube with diameter 
$7.5 \mathrm{~mm}$ and length $60 \mathrm{~mm}$ can be calculated as $30.9 \Omega$. The error in this modeling result is approximately $3.6 \%$ which is acceptable in simulation.

\subsection{Simulation of water electrolysis with different electrodes}

For investigating the electrode's contribution to the electrolysis process, two different electrodes are used as the cathode in the experiments when the tube length of the electrolytic cell is $70 \mathrm{~mm}$. To reduce the active area of the electrode, part of the platinum mesh was used as the cathode (approximately $10 \times 50 \mathrm{~mm}$ of Pt mesh) in the experiment. The water electrolysis started at potential $1.70 \mathrm{~V}$ with background current of $0.55 \mathrm{~mA}$. The water electrolysis parameters are obtained from the experimental data with: $E_{0}=1.7 \mathrm{~V}, \mathrm{~K}=0.0775 \Omega^{-1}$ and $r=40.7 \Omega$. In Fig. 5, the experimental results are shown as "Pt mesh" and the simulation results are shown as "Pt mesh modeling".

When a graphite electrode was used as a cathode and a platinum mesh as the anode, the water electrolysis started at potential $2.10 \mathrm{~V}$ with background current of $0.5 \mathrm{~mA}$. The water electrolysis parameters are obtained from the experimental data with $E_{0}=2.1 \mathrm{~V}, \mathrm{~K}=0.0381 \Omega^{-1}$ and $r=40.7 \Omega$. In Fig. 5, the experimental results are shown as "Graphite" and the simulation results with above parameters are shown as "Graphite modeling".

The experimental and simulation results show that a smaller active area of electrode reduces the overall kinetic effect of electrochemical reaction which is reflected in the value of a smaller power conversion coefficient $(K)$. Electrode materials not only influence the overall kinetic effect of the electrochemical reaction, but also influence the water dissociation potential, which is reflected in the value of the thermodynamic parameter $\left(E_{0}\right)$.

\subsection{Assumption validation}

The assumption in this model is expressed in equation (10). Fig. 6 validates the assumption by the linear relationship

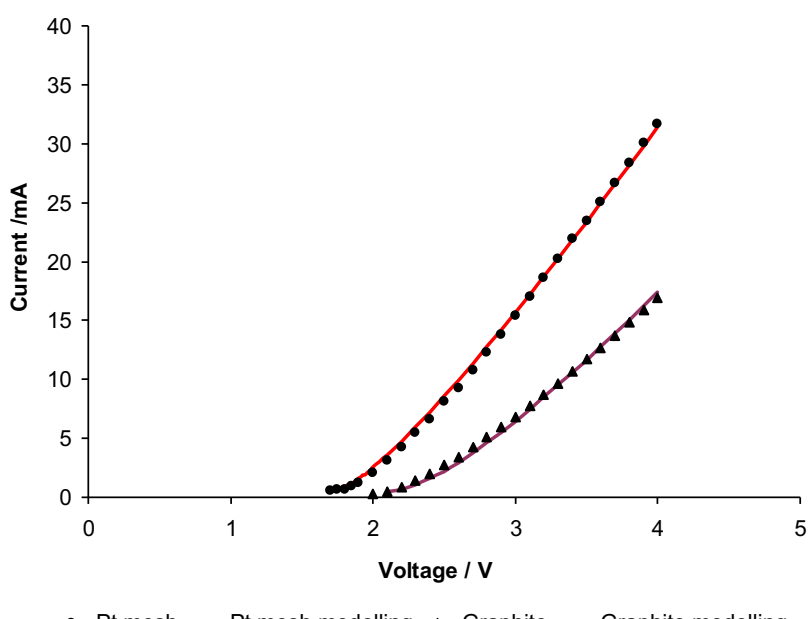

- Pt mesh — Pt mesh modelling ^ Graphite — Graphite modelling

Fig. 5 - Experiment data of water electrolysis with different electrodes and their modeling results with equation (13).

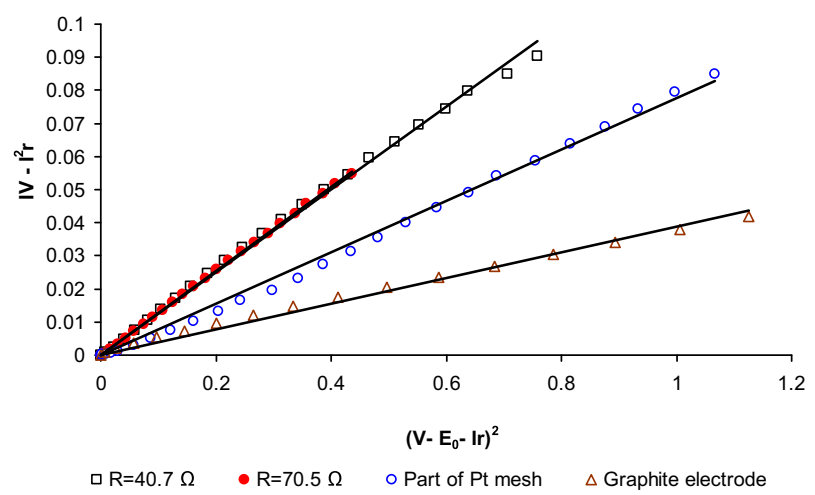

Fig. 6 - The linear relationship between the electrical power consumed in electrolysis process and the square of the potential difference applied on the electrodes.

between the electrical power consumed in the electrolysis process and the square of the potential difference applied on the electrodes. The power consumed in the electrolysis process is expressed as $\left(I V-I^{2} r\right)$. The square of the potential difference applied on the electrodes is expressed as $\left(V-E_{0}-I r\right)^{2}$. In Fig. 6, the data for water electrolysis with $\mathrm{Pt}$ mesh as electrodes are shown as " $R=40.7 \Omega$ " and " $R=70.5 \Omega$ " when their cell resistance is $40.7 \Omega$ and $70.5 \Omega$ respectively. The data for water electrolysis with the reduced part of Pt mesh as the cathode are shown as "Part of Pt mesh". The data for water electrolysis with the graphite stick as cathode are shown as "Graphite electrode". The electrical current data applied in Fig. 6 are modified by deducting the background current in the calculation.

\subsection{Simulation of water electrolysis in literature}

In the experiments, the adjustable cell tube is used for investigating the effect of the cell resistance in modeling. The values of cell resistances in the experiments are $40.7 \Omega$ and $70.5 \Omega$ which will cause a large potential drop and consume a large amount of electrical power if operating current is high. In practical application of hydrogen production, a small cell resistance is required for increasing the power efficiency. Millet et al. reported their present research work [9] in Proton Exchange Membrane water electrolysis with a small cell resistance and high operating current density. Fig. 7 shows the water electrolysis performances for different catalytic electrodes in the same operating conditions which may influence the cell resistance. The water electrolysis performances in Fig. 7 are described with relationship between current density and cell voltage. The unit of current density in the Fig. 7 is $\mathrm{mA} \mathrm{cm}{ }^{-2}$ which is different with previous expression in Figs. 4 and 5 when cell current $(\mathrm{mA})$ is used to validate the assumption. The temperature of PEM cell is $90^{\circ} \mathrm{C}$. When Pt is used for both electrodes, the water dissociation potential is $1.68 \mathrm{~V}$; the performance is plotted with black circle which is shown as Pt/ Pt in Fig. 7. When Pt is used as cathode and metal iridium is used as anode, the water dissociation potential is $1.4 \mathrm{~V}$; the performance is plotted with green circle which is shown as Pt/ Ir. When tungstosilicic acid hydrate $\left(\alpha-\mathrm{H}_{4} \mathrm{SiW}_{12} \mathrm{O}_{40}\right)$ is used as 


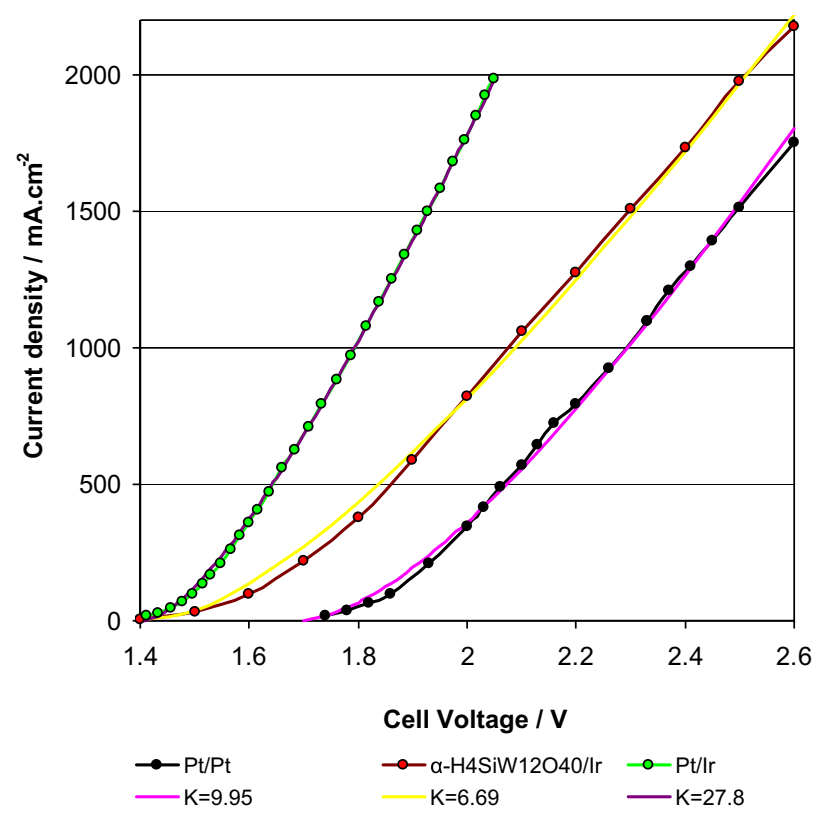

Fig. 7 - The literature [9] data of water electrolysis performance and their modeling results with equation (13).

electrocatalyst on cathode and metal iridium is used as anode, the water dissociation potential is $1.4 \mathrm{~V}$; the performance is plotted with red circle which is shown as $\alpha-\mathrm{H}_{4} \mathrm{SiW}_{12} \mathrm{O}_{40} / \mathrm{Ir}$. With the performance data, modeling results show the cell resistances are very small which is in the range from 0.134 to $0.172 \Omega \mathrm{cm}^{2}$. Actually, it is difficult to detect such small difference of cell resistance by experimentation. For simulating these water electrolysis performances, the average value of $0.15 \Omega \mathrm{cm}^{2}$ was used for cell resistance. Table 1 shows the water electrolysis parameters for these three groups of electrodes. Considering the operating currents in these performances are quite large, the error caused by the background current (normally less than $1 \mathrm{~mA}$ ) is negligible. The equation (13) is used to simulate the water electrolysis performance with relevant parameters in Table 1 . The simulating results are shown as " $K=9.95$ ", " $K=6.69$ " and " $K=27.8$ " in Fig. 7 for the electrolysis performance with electrodes of Pt/ Pt, $\alpha-\mathrm{H}_{4} \mathrm{SiW}_{12} \mathrm{O}_{40} /$ Ir and Pt/Ir respectively.

Fig. 8 shows the linear relationship between the electrical power consumed in an electrolysis process and the square of the potential difference applied on the electrodes for different catalytic electrodes in the literature [9]. The linear relationship validates the model assumption again in low cell resistance and high operating current density.

Table 1 - The water electrolysis parameters for different electrodes in literature [9]

\begin{tabular}{lccc} 
& $E_{0}(\mathrm{~V})$ & $\mathrm{K}\left(\Omega^{-1} \mathrm{~cm}^{-2}\right)$ & $r\left(\Omega \mathrm{cm}^{2}\right)$ \\
\hline $\mathrm{Pt} / \mathrm{Pt}$ & 1.68 & 9.95 & 0.15 \\
$\alpha-\mathrm{H}_{4} \mathrm{SiW}_{12} \mathrm{O}_{40} / \mathrm{Ir}$ & 1.4 & 6.69 & 0.15 \\
$\mathrm{Pt} / \mathrm{Ir}$ & 1.4 & 27.8 & 0.15 \\
\hline
\end{tabular}

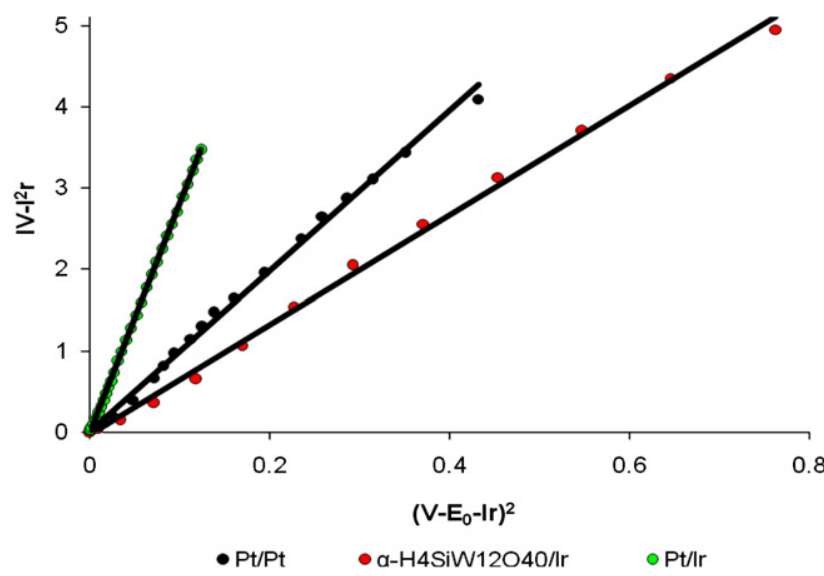

Fig. 8 - The linear relationship between the electrical power consumed in electrolysis process and the square of the potential difference applied on the electrodes [9].

\section{Conclusion}

The work proposes a concise model to describe water electrolysis performance by means of incorporating thermodynamic, kinetic and electrical resistance effects of the water electrolysis process for the first time. Compared with the Butler-Volmer kinetic equation, this model has fewer parameters and more convenient expression, which can be easily applied in simulating different electrolytic cells with various operating conditions. In comparison to the Tafel equation, the model avoids using a logarithmic function in its mathematical expression, providing a theoretic advantage of describing water electrolysis performance in both high and low operating currents. With this concise model, the characteristics of an electrolyte cell such as cell resistance and kinetic effects can be obtained directly from a cell performance curve which is advantageous for top-down analysis and electrolyte cell evaluation.

The modeling results in this paper agree well with experimental data and previous published work. The model is validated in experiments with different cell resistances, various electrode materials and different catalytic active areas. The validation of the assumption in the model, at both high and low operating currents, presents new understanding of electrochemistry.

\section{R E F E R E N C E S}

[1] Turner JA. Sustainable hydrogen production. Science 2004; 305:972-4.

[2] Ma L, Sui S, Zhai Y. Investigations on high performance proton exchange membrane water electrolyzer. Int J Hydrogen Energy 2009;34:678.

[3] Brisse A, Schefold J, Zahid M. High temperature water electrolysis in solid oxide cells. Int J Hydrogen Energy 2008; 33:5375.

[4] Ulleberg $\varnothing$. Modeling of advanced alkaline electrolyzers: a system simulation approach. Int J Hydrogen Energy 2003; 28:21. 
[5] Rasten E, Hagen G, Tunold R. Electrocatalysis in water electrolysis with solid polymer electrolyte. Electrochimica Acta 2003;48:3945.

[6] Yim SD, Park GG, Sohn YJ, Lee WY, Kim CS. Optimization of PtIr electrocatalyst for PEM URFC. Int J Hydrogen Energy 2005; 30:1345.

[7] Zhang Y, Wang C, Mao Z. Study on a novel manufacturing process of membrane electrode assemblies for solid polymer electrolyte water electrolysis. Electrochemistry Commun 2007;9:667.

[8] Sawada S, Yamaki T, Maeno T, Maekawa Y. Solid polymer electrolyte water electrolysis system for hydrogen production based on our newly developed membranes, Part I: analysis of voltage-current characteristics. Prog Nucl Energy 2008;50:443.

[9] Millet P, Ngameni R, Grigoriev SA, Mbemba N, Brisset F, Ranjbari A, et al. PEM water electrolyzers: from electrocatalysis to stack development. Int J Hydrogen Energy 2010;35:5043.

[10] Grigoriev SA, Porembsky VI, Fateev VN. Pure hydrogen production by PEM electrolysis for hydrogen production. Int $\mathrm{J}$ Hydrogen Energy 2006;31(2):171.

[11] Laoun B, Naceur M, Serir L. Electrochemical aided model to study solid polymer electrolyte water electrolysis. Revue des Energies Renouvelables 2008;11(2):267.

[12] Ni M, Leung Micheal KH, Leung Dennis YC. Electrochemistry Modeling of proton Exchange Membrane (PEM) water electrolysis for hydrogen production. In: Proceeding of the WHEC 16, Lyon, 13-16 June 2006.

[13] Choi P, Bassarabov DG, Datta R. A simple model for solid polymer electrolyte (SPE) water electrolysis. Solid State Ionics 2004;175:535.

[14] Onda K, Murakami T, Hikosaka T, Kobayashi M, Notu R, Ito K. Performance analysis of polymer-electrolyte water electrolytic cell at a small-unit test cell and performance prediction of large stacked cell. J Electrochem Soc 2002;149: A1069.

[15] Chan SH, Xia ZT. Polarization effects in electrolyte/electrodesupported solid oxide fuel cells. J Appl Electrochemistry 2002; 32(3):339.

[16] You L, Liu H. A Two-phase flow and transport model for PEM fuel cells. J Power Sources 2006;155(2):219.

[17] Millet P. Water electrolysis using EME technology: electric potential distribution inside a nafion membrane during electrolysis. Electrochim Acta 1994;39:2501.

[18] Bockris JO'M, Srinivasan S. Fuel cells: their electrochemistry. New York: McGraw-Hill; 1969.

[19] Shen M, Zhang J, Scott K. The general rule of power converted from chemical energy to electrical energy. Fuel Cells 2004;4(3):388.

[20] Robinson RA, Stokes RH. Electrolyte solutions. 2nd ed. London: Butterworths; 1959. p. 376.

[21] http://www.foxboro.com/NR/rdonlyres/84BD830F-DF724B63-A51B0D39220C518B/0/SulfuricAcidMeas.pdf. 